\title{
HXI open Cognitive ability and educational level in relation to concussion: a population study of young men
}

\author{
Thomas William Teasdale, Anna Julie Frøsig
}

To cite: Teasdale TW, Frøsig AJ. Cognitive ability and educational level in relation to concussion: a population study of young men. BMJ Open 2013;3: e002321. doi:10.1136/ bmjopen-2012-002321

\section{- Prepublication history for this paper are available online. To view these files please visit the journal online (http://dx.doi.org/10.1136/ bmjopen-2012-002321).}

Received 7 November 2012 Revised 15 January 2013 Accepted 12 February 2013

This final article is available for use under the terms of the Creative Commons Attribution Non-Commercial 2.0 Licence; see http://bmjopen.bmj.com

Department of Psychology, University of Copenhagen, Copenhagen, Denmark

Correspondence to Dr Thomas William Teasdale; tom.teasdale@psy.ku.dk

\section{ABSTRACT}

Objectives: To investigate the association of concussion with cognitive ability (CA) and educational level (EL).

Design: Epidemiological—cross-linkage of national computer registers.

Setting: Denmark.

Participants: 130420 young men appearing before the Danish draft board during the period 2006-2010.

Primary and secondary outcome measures: $\mathrm{CA}$ test scores, EL and occurrence of concussion during the period 2004-2009, treated either in an A\&E unit or upon admission to a hospital ward.

Results: The 3067 men who had suffered a concussion had lower CAs (mean=96.5, SD=15, 95\% $\mathrm{Cl} 95.0$ to 97.0 ) than the total cohort and they were lower for 1452 who were admitted to a hospital ward (mean CA=95.8, SD $=15,95 \% \mathrm{Cl} 95.1$ to 96.6) than for 1615 who were treated only at an A\&E unit (mean $\mathrm{CA}=97.1, \mathrm{SD}=15,95 \% \mathrm{Cl} 96.3$ to 98.0 ). Multiple logistic regressions revealed that the effects for $\mathrm{EL}$ were stronger than those for CA. Among 127353 men not sustaining a concussion, $48 \%$ attended a 'gymnasium' (sixth-form college), among men treated for a concussion at an A\&E unit, this falls to $36 \%$ and among men hospitalised for a concussion to $30 \%$. Transfer to a gymnasium, if it happens, almost invariably does so before the 18 th birthday. Among 701 men suffering a concussion and admitted to a hospital department after this date, only $26 \% \quad(n=182)$ were previously transferred to a gymnasium. Among the 804 men treated at an A\&E unit after their 18th birthday, 33\% $(n=265)$ had done so. These two percentages are significantly below the corresponding non-concussed population (48\%).

Conclusions: Taken together, the results suggest that lower CA and, in particular, lower EL are risk factors for sustaining a concussion, the risk increasing with the severity of the injury.

\section{INTRODUCTION}

A concussion, also often termed a mild traumatic brain injury, is defined as 'a trauma-induced alteration in mental status that may or may not involve loss of

\section{ARTICLE SUMMARY}

Article focus

- The role of cognitive ability (CA) and educational level (EL) in the occurrence of concussions.

Key messages

- Lower CA and, in particular, lower EL appear to be risk factors for sustaining a concussion, being found in individuals prior to sustaining a concussion.

- This risk increases with the severity of the injury.

Strength and limitations of this study

- The data are derived from a large, well-defined, population cohort.

- The data are limited to young men only and lack information on the severity of the injury other than whether it was treated in an A\&E unit or upon admission to a hospital.

consciousness'. ${ }^{1}$ It typically involves temporarily reduced consciousness and/or feelings of confusion and dizziness together with amnesia for events immediately preceding or following the injury. The consequences of concussions vary from transient symptoms to rarer instances of post-concussional syndrome with lasting physical, emotional, cognitive or behavioural symptoms. ${ }^{2}{ }^{3}$ Most studies, however, typically find that the cognitive effects of a concussion resolve themselves within days or at the most weeks. ${ }^{4-6}$

A number of risk factors for concussion have been identified. One of the major factors appears to be participation in sports, ${ }^{7}$ and, indeed, most studies about concussions concern sports-related injuries. ${ }^{8-10}$ Having previously sustained a concussion is a risk factor in itself, ${ }^{8}$ and the effects appear to be correspondingly cumulative. ${ }^{11} 12$

Gender and age are also significant risk factors for concussions, including those which are not the result of sports injuries. Concussions from all causes occur more often among males than among females and 
their incidences are particularly high among adolescents and young adults, but also peaking again among the elderly. ${ }^{13}$ Alcohol intoxication is an immediate risk factor for concussion $^{14}$ and sustaining a concussion while under the influence of alcohol has also been identified as a risk factor for further alcohol-related concussions. ${ }^{15}$

Although there has been extensive research investigating the cognitive effects of concussions, there has been relatively little research investigating the possible influence of education and cognitive functioning as risk factors. Ewing-Cobbs $e t a l^{16}$ found academic skill deficiencies to be present among adolescents prior to injury. Similarly, Teasdale and Engberg ${ }^{17}$ reported cognitive test performance to be reduced among young adults who subsequently sustained a concussion, even some years later. A relationship of educational and cognitive functioning with concussions could plausibly be expected given the pervasive association of social class-related characteristics with injuries in general. ${ }^{18}$

Four major difficulties with the extant studies have been the selectiveness of sampling, small samples, variability in the severity of the concussion (in particular, that many concussions sustained in sporting activities are comparatively quite mild) and the lack of good controls or test norms. The present study has attempted to overcome these difficulties. Our data are derived from a national medical database from which a large sample has been drawn and the concussions involved were medically diagnosed as such (International Classification of Diseases, tenth revision (ICD-10), S.060) and were of a severity sufficient to warrant at the least attendance at an A\&E unit. Specifically, as an indication of severity, we have been able to compare patients who were only treated at an A\&E unit with patients who were admitted to a hospital ward. Furthermore, for purposes of comparison, we have available full cognitive test scores and educational levels (ELs) for a complete population cohort: it is worth noting that this represents a considerable advance on the limited data available to us in previous studies where we had only cognitive test scores reduced to a dichotomy and no information on EL. ${ }^{17} 19$ Unusually, we are also able to report on the cognitive ability (CA) and EL of concussion patients either before or after the concussion occurred.

The present study thus examines the relationship of CA and EL with concussion, particularly with regard to the temporal order of events and the severity of concussion. In addition, we wished to explore the possible role of the cause of injury, specifically accident versus violence.

\section{METHODS}

\section{Draft board data}

The starting point for the present study was a database comprising all 159402 men processed by the Danish draft board in the 5-year period 2006-2010. Denmark maintains military conscription for which all men become liable at age 18 . The procedure entails, inter alia, a 45 min test for CAs, the Børge Prien's Prøve (BPP) which comprises four subtests for logical, verbal, numerical and spatial reasoning, each having about 20 items none of which are multiple choice. All of the subtests are measures of 'fluid' rather than 'crystallised' intelligence ${ }^{20}$ and all are timed; thus, mental speed is at a premium. The test result is the number of correct answers across subtests and out of 78 , but this CA score has here been converted to parallel conventional IQ scaling, viz. with a mean of 100 and an SD of 15, to give a more familiar metric of effect size. The BPP has been reported to correlate 0.82 with the Wechsler Adult Intelligence Scale ${ }^{21}$ and to have a test-retest reliability of $0.77 .^{22}$ Further details are reported elsewhere. ${ }^{23}$

Also recorded by the draft board is EL on an 8-13 scale primarily reflecting the highest school class attained. The most critical point on this scale is the divide between the values 8 through 10, which indicate just grade school, possibly followed by occupational training, and the values 11 through 13 which indicate that the individual has entered a 'gymnasium', equivalent to a 3-year sixth-form college and leading to a 'studentereksamen', akin to a baccalaureate and requisite for higher education. Entry to a gymnasium is contingent on examination results and teachers' recommendations and typically occurs at about the age of 16 .

In some cases, personal appearance before the board is not required and neither BPP nor EL are obtained. This occurs for men who, in advance, can document an illness which would disqualify them from military service, for example, chronic asthma, severe myopia and curvature of the spine. In the present cohort 28982 men $(18.2 \%)$ did not appear before the draft board. We obtained BPP and EL, together with the exact date of the draft board appearance, for the remaining 130420 $(81.8 \%)$ men. The average age for this appearance was 19.5 years (SD 1.3). Similarly to what has been reported elsewhere $^{22}$, the correlation between the BPP and EL was 0.52 . It is worth observing parenthetically that only a small proportion of the men who are processed by the draft board are thereafter called upon to perform military services, this being largely determined by the draw of a lottery number, once suitability has been established.

\section{Hospital registration data}

In Denmark, all hospital admissions and, since 2004, all treatments at A\&E units are centrally recorded in a National Hospitalization Register. ${ }^{24}$ Dates of admission or A\&E attendance are recorded. ICD-10 diagnoses are used and, in most cases, the cause of an injury is recorded using the Nordic Medico-Statistical Committee system. ${ }^{25}$ Primary among these causes in Denmark are accidents and, to a much lesser extent, violence.

For the 159402 men in our draft board database we searched this register for persons who, during the 
period 2004 through 2009, had been admitted to hospital, typically to an orthopaedic or a neurological ward, or were treated at A\&E units, in all cases with the sole discharge diagnosis of concussion (ICD-10 S.060). Cross-linking the two registers is made possible since both employ a national Central Person Registration number. For those admitted to hospital we restricted the period involved to not more than 2 days. The search identified 3847 men of whom 1830 had been admitted to hospital and 2017 had been treated at an A\&E unit. Approximately $4 \%$ of men who had sustained more than one concussion in the time period were recorded with the first of these. The hospitalisation register does not include information on loss of consciousness or posttraumatic amnesia. Among the two groups, respectively, $1452(79.3 \%)$ and $1615(80.1 \%)$ had appeared before the draft board and for whom BPP and EL were thus available. It is worth noting that these percentages differ significantly, $\left(\chi^{2}(2)=12.0, \mathrm{p}<0.01\right)$ but only slightly, from the above-noted overall rate of $81.8 \%$. The mean age at injury for all patients was 17.9 years (SD 2.5). The ages ranged between 11 and 31 years, but $90 \%$ were between 14 and 22 years. Among those for whom BPP and EL were available, 1887 cases $(62 \%)$ were coded as 'accident' and 447 cases (15\%) were coded as 'violence'. These codes were lacking for the remaining 733 (24\%).

Table 1 shows age at injury and age at testing, separately for admitted patients and for A\&E patients, in relation to the injury occurring before or after draft board testing, together with age at testing for the non-patient group. It can be seen that there are no differences between the five defined groups in age at testing. Age at injury was (necessarily) earlier for those injured before testing and later for those injured after testing. Among the four patient groups a significantly higher proportion of those injured before testing were admitted to hospital rather than treated in A\&E (49.5\%) than among those injured after testing $(40.5 \%) \quad\left(\chi^{2}(1)=18.5, \mathrm{p}<0.001\right)$. Among those injured before testing the median time interval was 819 days for admitted patients and 797 days for A\&E patients (Mann-Whitney $\mathrm{U}, \mathrm{z}=0.64$, n.s.).

\section{Statistics}

The data were analysed with SPSS V.20, using t tests, analyses of variance including a priori contrasts, logistic regression and ORs.

\section{RESULTS}

Means and SDs for CA and EL as functions of patient type and being tested postconcussion or preconcussion, together with the non-concussed group, are shown in table 2. Overall $\mathrm{t}$ tests showed that concussion patients had significantly lower CA (t (130 418)=13.2, p<0.001) and significantly lower EL (t (130 418)=18.8, p<0.001) than those among non-patient population. The CA difference was 3.6 points, corresponding to an effect size of 0.24 (Cohen's $\mathrm{d}^{26}$ ) and the effect size for EL was 0.35.
Table 1 Mean ages and frequencies as a function of concussion pretesting or post-testing and without concussion

\begin{tabular}{|c|c|c|c|}
\hline & $\begin{array}{l}\text { Age at } \\
\text { injury, } \\
\text { mean (SD) }\end{array}$ & $\begin{array}{l}\text { Age at } \\
\text { testing, } \\
\text { mean (SD) }\end{array}$ & $\mathbf{n}$ \\
\hline \multicolumn{4}{|c|}{ Admitted patients } \\
\hline $\begin{array}{l}\text { Concussion } \\
\text { pretesting }\end{array}$ & $17.2(2.0)$ & $19.6(1.3)$ & 1152 \\
\hline $\begin{array}{l}\text { Concussion } \\
\text { post-testing }\end{array}$ & 20.5 (1.4) & $19.4(1.1)$ & 300 \\
\hline \multicolumn{4}{|l|}{ A\&E patients } \\
\hline $\begin{array}{l}\text { Concussion } \\
\text { pretesting }\end{array}$ & $17.1(2.0)$ & $19.5(1.4)$ & 1174 \\
\hline $\begin{array}{l}\text { Concussion } \\
\text { post-testing }\end{array}$ & $20.6(1.5)$ & $19.4(1.1)$ & 441 \\
\hline Non-patients & & $19.5(1.3)$ & 127353 \\
\hline
\end{tabular}

With the single exception of the CA score for individuals suffering a concussion subsequent to testing and treated at an A\&E unit, all comparisons between the individual concussion groups shown in table 2 and the non-patient group are statistically significant $\mathrm{p}<0.01$.

To examine for effects of hospital admission versus A\&E treatment and of sequence of injury and testing we conducted analyses of variance for CA and EL in which the non-patient group was excluded and preinjury or postinjury and patient type were included as independent variables. For CA there were significant main effects of pre-postinjury $(\mathrm{F}(1,3063)=11.1, \mathrm{p}=0.001)$ and of patient type $(\mathrm{F}(1,3063)=4.5, \mathrm{p}=0.033)$. The interaction was not, however, significant $(\mathrm{F}(1,3063)=0.7$, n.s. $)$. Overall, men injured before testing had CAs on average 2.3 points below those of men injured after testing, an effect size of $d=0.15$. Those who were admitted to hospital had CAs on average 1.2 points below those who were treated in A\&E units, an effect size of $d=0.08$.

Table 2 Cognitive ability (CA) and educational level (EL) as a function of concussion pretesting or post-testing and without concussion

\begin{tabular}{|c|c|c|}
\hline & $\begin{array}{l}\text { CA, mean } \\
\text { (SD) }\end{array}$ & $\begin{array}{l}\text { EL, mean } \\
\text { (SD) }\end{array}$ \\
\hline \multicolumn{3}{|l|}{ Admitted patients } \\
\hline Concussion pretesting & $95.5(14.9)^{\star}$ & 10.2. $(1.7)^{\star}$ \\
\hline $\begin{array}{l}\text { Concussion } \\
\text { post-testing }\end{array}$ & $97.1(14.9)^{*}$ & $10.2(1.7)^{*}$ \\
\hline \multicolumn{3}{|l|}{ A\&E patients } \\
\hline Concussion pretesting & $96.3(14.8)^{\star}$ & $10.4(1.8)^{\star}$ \\
\hline $\begin{array}{l}\text { Concussion } \\
\text { post-testing }\end{array}$ & $99.0(14.9)$ & $10.6(1.8)^{*}$ \\
\hline All patients & $96.5(14.9)^{*}$ & $10.3(1.8)^{*}$ \\
\hline Non-patients & $100.1(15.0)$ & $11.0(1.8)$ \\
\hline
\end{tabular}


For EL there was no main effects of pre-postinjury ( $\mathrm{F}$ $(1,3063)=0.8$, n.s. $)$ but there was a significant effect of patient type $(\mathrm{F}(1,3063)=15.6, \mathrm{p}<0.001)$. The interaction was again not significant $(\mathrm{F}(1,3063)=0.7$, n.s. $)$. Patients admitted to hospital had lower EL than those treated in A\&E units (effect size, $d=0.15$ ).

In order to investigate the degree to which CA and EL are independently related to the occurrence of a concussion we included both variables, transformed to $\mathrm{z}$ scores to enable comparison of their respective contributions, in a logistic regression predicting concussion. The Nagelkerke $\mathrm{R}^{2}$ was 0.014 . The resulting model is shown in table 3 where it can be seen that both EL and CA predict concussion significantly, but that the contribution of EL is markedly and significantly greater than that of CA.

We have explored further the potential role of EL specifically as a risk factor for concussion. As stated above, within the EL scale from 8 to 13 , the most salient dichotomy is between 8 and 10, representing those who only attended grade school ('folkeskole', typically dropping at the age of 15 or 16 and pursuing non-academic further education) and 11-13, representing those who went onto the academically oriented gymnasium. Since we do not know the exact age at which an individual transferring to a gymnasium actually did so, we selected men whose concussions occurred after their 18th birthday since transfer would almost certainly have happened before that date. The numbers of these men were compared with a baseline of those men in the present sample who did not sustain a concussion and who did attend a gymnasium (61 645 of $127353=48 \%$ ).

Among the 701 men who sustained a concussion after their 18th birthday and for which they were admitted to a hospital, 26\% (n=182) had entered a gymnasium, this being significantly below the baseline $(\mathrm{OR}=0.37,95 \%$ CI 0.32 to 0.44 ). Among the 804 men who sustained a concussion after their 18th birthday and for which they were treated at an A\&E department, 33\% (n=265) had entered a gymnasium, this again being significantly below the baseline $(\mathrm{OR}=0.52,95 \%$ CI 0.45 to 0.61$)$. The percentage of men attending gymnasium within these two concussion groups was significantly lower for those admitted to a hospital than for those treated at an A\&E unit (OR=0.71, 95\% CI 0.57 to 0.89 ).

Given previous evidence of cognitive dysfunction for a comparatively short period following a concussion we examined CA scores for 26 patients who were tested within 30 days after being injured. However, this group had a mean CA of 95.3 (SD 15.3) which did not differ significantly from all others who were injured prior to being tested, mean $\mathrm{CA}=95.9$, (SD 14.8) $(\mathrm{t}(2327)=0.2$, n.s. $)$.

The two main causes of injury were 'accident' $(n=1905$, $62 \%$ ) and 'violence' (458, 15\%). Mean CA and EL for these two groups are shown in table 4 . The majority of the remaining causes of injury were either not coded or recorded as 'other'. Patients with injuries associated with violence had significantly lower CAs $(\mathrm{t}(2334)=2.02$, $\mathrm{p}<0.05)$ and significantly lower ELs $(\mathrm{t}(2361)=3.61$, $\mathrm{p}<0.001)$ than patients with accidental injuries. Again, the effect size is greater for EL $(d=0.24)$ than for CA $(\mathrm{d}=0.11)$.

\section{DISCUSSION}

The main finding of the present study is that lower CA and, in particular, lower EL appears to be risk factors for sustaining a concussion, the risk increasing with the severity of the injury. It is, however, recognised that the study has a number of limitations. First, we have only had data available on males and it is therefore uncertain whether the present findings would apply also for females. It should be added, however, that males account for a much greater incidence of concussions than do females. ${ }^{13} 27$ A second limitation is the narrow age range of our sample which, for reasons related to the available databases, was limited to concussions occurring predominantly between the ages of 14 and 22 . Again it could be added that the age range to which we perforce have been limited to is exactly a high-risk period for concussions. ${ }^{13}$ A third limitation is the lack of conventional measures of the severity of a concussion, such as duration of unconsciousness or post-traumatic amnesia.

These limitations notwithstanding, a number of conclusions can be drawn. The major conclusion is that both relatively low $\mathrm{CA}$ and EL are associated with the occurrence of a concussion. We found lower levels of CA and EL for men who had suffered a concussion both when the concussion had occurred prior to testing, and, importantly, when it occurred subsequent to testing. The fact, however, that the effect for CA was also greater for men who had suffered a concussion prior to being tested by the draft board, than among those whose concussion occurred after testing is contrary to an earlier finding of the reverse pattern. ${ }^{17}$ It should, however, be

Table 3 Logistic regression of cognitive ability (CA) and educational level (EL) (both standardised to z scores) in relation to concussion

\begin{tabular}{|c|c|c|c|c|c|c|c|c|}
\hline & \multirow[b]{2}{*}{ Log OR } & \multirow[b]{2}{*}{ SE } & \multirow[b]{2}{*}{ Wald } & \multirow[b]{2}{*}{ df } & \multirow[b]{2}{*}{ Significance of $p$ values } & \multirow[b]{2}{*}{ OR } & \multicolumn{2}{|c|}{ OR $95 \% \mathrm{Cl}$} \\
\hline & & & & & & & Lower & Upper \\
\hline CA & -0.072 & 0.021 & 12.43 & 1 & 0.001 & 0.930 & 0.893 & 0.968 \\
\hline EL & -0.315 & 0.022 & 198.57 & 1 & 0.001 & 0.730 & 0.698 & 0.762 \\
\hline Constant & -3.786 & 0.019 & 38293 & 1 & 0.001 & 0.023 & & \\
\hline
\end{tabular}


Table 4 Cognitive ability (CA) and educational level (EL) as a function of cause of injury

$$
\text { CA, mean (SD) }
$$

EL, mean (SD)

Accident

$96.6(15.0)$

Violence $95.0(14.6)$

$10.4(1.8)$

noted that the age range for injuries is much narrower, and the sample size much larger in the present study. Furthermore, the earlier study used a very limited dichotomous scoring of the BPP test and did not include a measure of EL.

Whatever accounts for this pretesting and post-testing CA effect it seems unlikely that it is largely attributable to a direct causal effect of the injury on later CA test scores. The average pretesting interval in the present sample was 2.4 years, whereas most studies finding direct effects of concussion on cognitive functioning report much shorter intervals. ${ }^{4-6} 17$ A further reason to discount a direct effect of the concussion is that we did not find reduced test performance in those patients for whom the concussion-to-testing interval was within a range more commonly reported, that is, 1 month. It is recognised that the possibility cannot be discounted that some proportion of the men injured prior to testing have been suffering post-concussional syndrome in which, among other symptoms, poor attention and fatigue can continue for long after the injury. ${ }^{4}$ 28-30 Such cases would depress both the CA scores and EL. However, it should be observed that post-concussional syndrome is more characteristic of women than men and of older rather than younger persons. ${ }^{31}$

The consistency with which the associations of concussion are greater with EL than with CA may in part result from the lower reliability of the BPP test. It is, however, particularly striking that among the young men who had suffered a concussion after attaining the age of 18 , by which time any transfer to higher education (gymnasium) would have occurred, substantially fewer in fact had done so. Whereas about $48 \%$ of men in general had attended a gymnasium, only $26 \%$ of men admitted to a hospital for a concussion had done so and only $33 \%$ of men treated at an A\&E unit had done so. This strongly implicates EL as a risk factor for sustaining a subsequent concussion, and the difference between hospital admission and A\&E treatment further suggests that the risk is greater for relatively more severe injuries.

It is tempting to speculate that both CA and EL in the present study are indicators for broader social environmental factors which appear to contribute to injury risks in wider contexts. ${ }^{18}$ It is beyond the scope of the present study to investigate such factors more closely, but the frequent involvement of alcohol in incidences of concussion $^{31} 32$ and our finding that violence as a cause of injury is more strongly associated with lower EL and CA than is accident, also suggests that social factors are operating. ${ }^{32}$

Contributors TWT was responsible for the acquisition of data. Both authors made substantial contributions to the conception and design, and the interpretation of results. TWT bore primary responsibility for the statistical analyses and AJF bore primary responsibility for reviewing the relevant literature. Both authors have collaborated in drafting the article and both have given the final approval of the version to be published.

Funding This research received no specific grant from any funding agency in the public, commercial or not-for-profit sectors.

Competing interests None.

Provenance and peer review Not commissioned; externally peer reviewed.

Data sharing statement No additional data are available.

\section{REFERENCES}

1. American Academy of Neurology. Practice parameter: the management of concussion in sports (summary statement). Report of the Quality Standards Subcommittee. Neurology 1997;48:581-5.

2. Ruff RM, Iverson GL, Barth JT, et al. Recommendations for diagnosing a mild traumatic brain injury: a National Academy of Neuropsychology education paper. Arch Clin Neuropsychol 2009;24:3-10.

3. Moldover JE, Goldberg KB, Prout MF. Depression after traumatic brain injury: a review of evidence for clinical heterogeneity. Neuropsychol Rev 2004;14:143-54.

4. Daneshvar DH, Riley DO, Nowinski CJ, et al. Long-term consequences: effects on normal development profile after concussion. Phys Med Rehabil Clin N Am 2011;22:683-700, ix.

5. Makdissi M. Sports related concussion-management in general practice. Aust Fam Physician 2010;39:12-17.

6. Ponsford J, Willmott C, Rothwell A, et al. Cognitive and behavioral outcome following mild traumatic head injury in children. $J$ Head Trauma Rehabil 1999;14:360-72.

7. Daneshvar DH, Nowinski CJ, McKee AC, et al. The epidemiology of sport-related concussion. Clin Sports Med 2011;30:1-17, vii.

8. Schulz MR, Marshall SW, Mueller FO, et al. Incidence and risk factors for concussion in high school athletes, North Carolina, 19961999. Am J Epidemiol 2004;160:937-44.

9. Koh JO, Cassidy JD, Watkinson EJ. Incidence of concussion in contact sports: a systematic review of the evidence. Brain Inj 2003;17:901-17.

10. Hollis SJ, Stevenson MR, McIntosh AS, et al. Mild traumatic brain injury among a cohort of rugby union players: predictors of time to injury. Br J Sports Med 2011;45:997-9.

11. Guskiewicz KM, McCrea M, Marshall SW, et al. Cumulative effects associated with recurrent concussion in collegiate football players: the NCAA Concussion Study. JAMA 2003;290:2549-55.

12. Moser RS, Iverson GL, Echemendia RJ, et al. Neuropsychological evaluation in the diagnosis and management of sports-related concussion. Arch Clin Neuropsychol 2007;22:909-16.

13. Engberg AW, Teasdale TW. Traumatic brain injury in Denmark 1979-1996. A national study of incidence and mortality. Eur $J$ Epidemiol 2001;17:437-42.

14. Sperry JL, Gentilello LM, Minei JP, et al. Waiting for the patient to 'sober up': effect of alcohol intoxication on Glasgow Coma Scale score of brain injured patients. J Trauma 2006;61:1305-11.

15. Winqvist $\mathrm{S}$, Luukinen $\mathrm{H}$, Jokelainen $\mathrm{J}$, et al. Recurrent traumatic brain injury is predicted by the index injury occurring under the influence of alcohol. Brain Inj 2008;22:780-5.

16. Ewing-Cobbs L, Fletcher JM, Levin HS, et al. Academic achievement and academic placement following traumatic brain injury in children and adolescents: a two-year longitudinal study. J Clin Exp Neuropsychol 1998;20:769-81.

17. Teasdale TW, Engberg A. Duration of cognitive dysfunction after concussion, and cognitive dysfunction as a risk factor: a population study of young men. BMJ 1997;315:569-72.

18. Gottfredson LS. Intelligence: is it the epidemiologists' elusive 'fundamental cause' of social class inequalities in health? J Pers Soc Psychol 2004;86:174-99.

19. Teasdale TW, Engberg AW. Cognitive dysfunction in young men following head injury in childhood and adolescence: a population study. J Neurol Neurosurg Psychiatry 2003;74:933-6.

20. Gregory RJ. Psychological testing: history, principles and applications. 6th edn. Boston: Pearson, 2011.

21. Mortensen EL, Reinisch JM, Teasdale TW. Intelligence as measured by the wais and a military draft board group test. Scand J Psychol 1989;30:315-18. 
22. Teasdale TW, Hartmann PVW, Pedersen $\mathrm{CH}$, et al. The reliability and validity of the Danish Draft Board Cognitive Ability Test: Borge Prien's Prove. Scand J Psychol 2011;52: 126-30.

23. Teasdale TW. The Danish Draft Board's intelligence test, B circle divide rge Priens $\mathrm{Pr}$ circle divide ve: psychometric properties and research applications through 50 years. Scand J Psych 2009;50:633-8.

24. Andersen TF, Madsen M, Jorgensen J, et al. The Danish National Hospital Register. A valuable source of data for modern health sciences. Dan Med Bull 1999;46:263-8.

25. Engberg AW, Penninga EI, Teasdale TW. [Nordic accident classification system used in the Danish National Hospital Registration System to register causes of severe traumatic brain injury]. Ugeskr Laeger 2007;169:3856-60.

26. Howell DC. Statistical methods for psychology. 6th edn. Belmont, CA: Thomson Wadsworth, 2007
27. Cassidy JD, Carroll LJ, Peloso PM, et al. Incidence, risk factors and prevention of mild traumatic brain injury: results of the WHO Collaborating Centre Task Force on mild traumatic brain injury. $J$ Rehabil Med 2004;36(43 Suppl):28-60.

28. Boake C, McCauley SR, Levin HS, et al. Limited agreement between criteria-based diagnoses of postconcussional syndrome. J Neuropsychiatry Clin Neurosci 2004;16:493-9.

29. Ruff RM. Mild traumatic brain injury and neural recovery: rethinking the debate. NeuroRehabilitation 2011;28:167-80.

30. Williams WH, Potter S, Ryland H. Mild traumatic brain injury and postconcussion syndrome: a neuropsychological perspective. J Neurol Neurosurg Psychiatry 2010;81:1116-22.

31. Ryan LM, Warden DL. Post concussion syndrome. Int Rev Psychiatry 2003;15:310-16.

32. Demellweek C, Baldwin T, Appleton R, et al. A prospective study and review of pre-morbid characteristics in children with traumatic brain injury. Pediatr Rehabil 2002;5:81-9. 